Gazette qualified men as regimental surgeons, raise their pay, but not their rank, at fixed intervals-say of three years; make them subject to military control and to the orders of administrative medical officers in non-medical matters, but quite independent in the practice of their profession; and let the duties of the administrative staff be those of supervision and of providing extra medical aid where and when required, and of receiving and inspecting the returns required by the rules of the service. I would go even further, and say that it is quite unnecessary that the Army Medical Board in London should be so largely composed of medical officers. Retain a head-quarter administrative staff there, hand over the selection of candidates to examining boards at the capitals of the three kingdoms, and transfer much of the mechanical work of the department to non-medical officials.

Pray excuse so long a letter.

Yours faithfully,

JAMES Johnston, M.D.,

Edinburgh, 10th Angust, 1878. Late Regimental Surgeon.

\section{OBSTRUCTION OF THE BOWELS.}

\section{To the Editor of THE LANCET.}

SIR, - The following case may be interesting to many of the readers of your journal :-

E. S-, a grocer, aged twenty-four, well nourished, of a habitually costive nature, frequently having gone for three days at a time without any action of the bowels, was seized on February 6 th with pains in the belly, constant vomiting, and the passage of much flatus. Becoming worse in the night, he sent for the nearest medical man, who gave him a draught. This was rejected. A dose of morphia, hypodermically, however, staid the sickness, and produced sleep. The symptoms returned in the morning. I was sent for about midday. I found him in great pain, most severe over the right iliac region, where was discernible a decided fulness, which was resistent to the touch and dull on percussion. The pain, aggravated on manipulation, extended along the course of the larger bowel. The abdomen was distended. The bowels had not acted properly since the 4th. The usual seats of hernia displayed nothing. Pulse 98, full; temp. $102^{\circ} \mathrm{F}$; resp. normal. Ordered half an ounce of castor oil to be taken at once; half a grain of opium, with a grain of calomel, in pill every four hours ; a soda mixture, containing a little lemon and hydrocyanic acid; ice to suck ; turpentine stupes to belly; at night the sixth of a grain of morphia subcutaneously. From this time up to the 11th he gradually became worse, passing nothing by the bowel, in spite of an enema of castor oil and turpentine every morning and enemata of warm water and soapsuds every four hours. There was constant vomiting, with hiccough, and much tympanites. The pulse ranged from 96 to 112 ; the temperature from $1024^{\circ}$ to $100^{\circ}$; the breathing was hurried, and entirely thoracic.

Feb. 11th.-Ordered an anema containing one grain of the extract of belladonna to six ounces of warm water; and extract of belladonna pill, one-sixth of a grain.

12th. - Two stercoraceous vomits; no action of the bowels. Pulse 102, feeble; temp. $100^{\circ}$; resp. 28 . Ordered eight grains of calomel to be taken at once, to be followed in three hours' time by an enema of as much warm water as could be passed up. The calomel produced a deal of rumbling, and the injection, about three pints, returned, decidedly fæcal.

13th. - Belly less distended. Three stercoraceous vomits. To go on with the injections every six hours. A milk and beef-tea diet.

14th.- Two biliary vomits. Two motions, after injections, containing scybala. From this date he began to improve. Ordered tish, eggs, \&c. ; and two-grain doses of quinine three times a day. The pain and fulness which were noticed at the commencement of the attack remain unaltered.

23rd-_Swelling increased in size. Very painful. To be painted, night and morning, with the tincture of iodine.

March 25th.-Swelling larger, with indistinct fluctuation. Ordered poppy fomentations, and linseed-meal poultices sprinkled with laudanum.

April 12th.-The swelling, which has been slowly in. creasing, is now of an immense size, fully five inches in diameter every way. Very prominent, with marked fluctuation. Patient will not consent to have it lanced. Ordered a pint of stout a day.

14th. - The abscess broke to-day, and discharged about three-quarters of a pint of sanious and most stinking pus.

May 4th.-Suppuration ceased; wound healed.

18th.-Patient improved in health, and increased in weight.

July 4 th. - Complains of a weakness over the spot where the abscess broke. Advised to wear some kind of support, in addition to the flannel binder he has worn since May 4th.

In my opinion the case commenced as one of typhlitis, set up no doubt by the frequent irritation of accumulated fæces; followed by the intestinal obstruction, and eventually giving rise to perityphlitis, and the formation of abscess, which fortunately pointed and discharged externally.

Lastly, as to my line of treatment in the above case, I think that,-taking into consideration the fact of the symptoms pointing to some perityphlitic mischief, and bearing in mind the serious nature of the case, which was sure to end fatally if the bowels remained closed, and knowing what a hazardous and unsatisfactory undertaking it is to operate in these cases, - I was justified in giving the laroe dose of calomel, rather than having resort to the dread alternative of opening the abdomen.

Cardiff, August 13th, 1878. am, Sir, yours truly

\section{THE MANCHESTER EXPERIMENT IN PROVIDENT DISPENSARIES.}

\section{To the Editor of THE LANCET.}

SrR, - A report of a Sub-Committee of the Midland Counties Branch of the British Medical Association and the Midland Medical Society on the subject of Provident Dispensaries has been put into my hands, in which I find the following passages :-

"The experience of Manchester is conclusive as to the necessity of proceeding most cautiously, if existing evils are to be remedied without incurring the risk of adding an equally great one under another name. Although in that city guarantors have for some years paid in round numbers $£ 1000$ per annum in aid of provident dispensaries, the members subscribing to them have largely diminished, and the scheme has failed to commend itself to the local members of the medical profession.

"Notwithstanding such experience, individual members of our Societies are free to act according to their judgment and inclination; but, as representatives of the profession, our Committee have declined to take part in a scheme in which failure seems inevitable while the local medical charities are administered as at present."

I am not acquainted with the full scheme proposed for the Birmingham provident dispensaries, but as the above quota. tions pronounce failure to be inevitable, and refer to Manchester for illustration, it may be as well to show how far Manchester has failed, and the reasons thereof.

The promoters of the Manchester scheme intended to follow the lines which have led to success in Northampton, Coventry, Leicester, and Derby, and to combat the abuses of the medical charities by bringing efficient medical aid within the means of the working classes generally, hoping that appeals to their feelings of self-reliance and independence would attract the bulk of the well-conducted to these institutions. Some members of the medical profession suggested that if the medical charities could be induced to co-operate, and to refuse assistance to all applicants who were found able to pay dispensary fees, then we could at once stamp out the abuse of those charities and provide the remedy. Now, in order to secure this co-operation, it was found necessary to restrict admission to the provident dispensaries to families in receipt of not more than $30 \mathrm{~s}$. per week average wages. For the sake of securing this valuable co-operation, and of speedily remedying the abuse of the charities, this restriction was submitted to ; but, as we were not able to cover the two boroughs with provident dispensaries, and as several of the charities have not come into the scheme, the provident dispensaries have had their sphere of 
action greatly restricted, and have still to compete with institutions whose abuses they started to remedy. Now the medical charities could not be carried on without honorary medical officers, and these latter can govern the proceedings of the hospitals. The inevitable conclusion is, therefore, that the medical men connected with the charities which have not joined in the scheme are not in earnest in their wish to reform the abuses of their institutions.

Here, then, is the first element of our partial failure, resulting not from any defect in the scheme of provident dis. pensaries, but from our having aimed at too much, considering the materials we have had to work with. We unfortunately admitted on our staff all qualified medical men who chose to apply, and as a result the income obtained by some was not sufficient to satisfy them; whilst others after they had got a goodly number of patients, left us, and endeavoured to take the patients with them. In addition to this there was a great flock of sick people who came to us whilst there was no entrance-fee to pay, and who left as soon as they became convalescent; so that it is not difficult to understand why Manchester has not done better, nor will it be difficult for Birmingham to avoid our errors.

But what is the extent of our failure? We had six provident dispensaries, with 11,370 paying members, at the end of last year, and these are now on the increase. The $£ 1000$ a year provided by the guarantors has covered establishment charges, including fittings, surgical implements, and stocks of drugs. One of the dispensaries is now selfsupporting, a second cost the council only about $£ 50$ last year, and will, I trust, cost less this year. Upon the whole, the requirements from the council are now not more than $£ 500$ per annum, and they are not likely to be increased unless we open more dispensaries; and even if the aid of the council should cease, it is very unlikely that the provident dispensaries would be given up.

The alternative I should like to lay before the medical profession is this-Will they join the provident dispensaries in this way, helping the working classes to form habits of self-reliance, and at the same time putting an end to the abuse of medical charities ; or will they encourage the benevolent public still to offer a premium on mendicity, and thus prevent that growth of independence and forethought which the provident dispensaries render possible? The report of the committee which I am now discussing admits that for many years the recipients of medical charities in Birmingham have increased " in a far greater proportion than the population," and they furthur admit that "to encourage such abuse, or permit it to continue, is to foster improvidence and fraud." I presume this committee would also admit that a considerable proportion of the working classes, if they have sickly families, cannot possibly pay the ordinary medical fees, and that for them the provident dispensaries would be a great blessing, enabling them to avoid the dangers of debt.

Some combination is evidently necessary for the cure of these numerous evils, and it seems to me that those who oppose or seek to delay the establishment of provident dispensaries are bound in honour to produce a better scheme for the purpose. This the medical committee has not only failed to do, but, by misrepresenting what has been done in Manchester, it seems to be their desire to prevent others from remedying the evils by means known to have been successful elsewhere.

$$
\text { I am, \&c., JoHN WATTS, }
$$

Chairman of Provident Dispensary. Rawson-street, Manchester, August 5th, 1878.

* * The above letter continues a discussion of the greatest interest both in a social and professional respect, and one upon which we shall have something more to say ere long. A serious feature in this letter is the extent to which it blames medical men for the slow and partial success at Manchester. We shall only at present make one more remark on Mr. Watts's interesting communication. He mentions the successful instances of provident dispensaries at Northampton, Coventry, Leicester, and Derby. We are not aware that in these towns the medical charities or the medical men have acted differently from the way in which it is complained they have acted in Manchester, from which we should infer the necessity for some other explanation of the different results.-ED. $\mathbf{L}$.

\section{POOR-LAW EXCUSES FOR NON-PAYMENT OF FEES.}

To the Editor of THE LANCET.

SIR,-I should be glad if some one of your readers-and there must be many who know-would kindly inform me on the following question, as to whether the Board of Guardians are right or wrong; and if wrong, how shall I be able to ascertain the law on the subject, and obtain redress?

A man breaks his leg, and, under ordinary circumstances, as district medical officer, I should be summoned to attend him; an order would be given by the relieving officer, and in due time I should obtain my fee. However, in the present case, the patient is removed to the Cottage Hospital-also within my district, -and I, as district medical officer, am fetched to attend him. I do so attend, and set his fracture. The Board refuse to grant an order (which carries the fee), on the grounds that "the leg was set in the hospital."

I am not a surgeon to the Cottage Hospital, either paid or honorary, but have, in common with all medical practitioners here, the privilege of attending my own patients if admitted as such; so also patients admitted without any regular medical attendant can, if they express the wish, be attended by any one they choose, or, in default of an expressed choice, by the hon. surgeon. Patients contribute a certain sum weekly towards their maintenance.

If I am to be deprived of my fees in this way, I shall be mulcted in a considerable sum every year that the guardians are otherwise bound to pay, or else I must refuse for the future to admit any parish cases, and so a great many sufferers will be deprived of skilled nursing and all the many advantages of a Cottage Hospital over a poor man's home. I am, Sir, yours obediently.

Surbiton, August 14th, 1878. OWEN COLEMAN, M.D。

\section{KOUMISS IN DIABETES. To the Editor of THE LANCET.}

SIR,-On the 6th January, B. D-, aged twenty-nine years, presented himself at my consulting-room with all the symptoms of diabetes. His pulse was 100 ; weight $8 \mathrm{st} .7 \mathrm{lb}$.; bowels constipated; passed eighteen pints of urine in twenty-four hours, and sugar was present in it in considerable quantities. Had a very jaundiced appearance. Could not lie long without having to get up to pass urine. For some considerable time before the above date he was under my care for this disease, and, after other attempts to alleviate his symptoms unsuccessfully, was put upon skim-milk treatment. Upon this he improved for a time, so much so, indeed, as to be able to resume work, which he had been obliged to give up. This did not continue, however, and he gave it up and was soon obliged to present himself again. He was rapidly losing flesh and strength. Having not long before this read an account of some cases in THE LANCET that were benefited by koumiss, I determined to give it a trial, and ordered an ounce five or six times a day.

Jan. 11th.-Says he feels better. Pulse 98. Is not so jaundiced in appearance. Bowels open every day ; passed in twelve hours, from 6 o'clock last evening to 6 o'clock this morning, eight pints of urine, carefully measured, of sp. gr. 1036.

I will not trouble you with particulars of every examination, but say that from this date to the 31st of March he continued this treatment, and that the improvement was remarkable. On the 31st of March the urine passed in twenty-four hours was five pints (a great diminution com. pared with eighteen pints on the 6th of January), its sp. gr. being 1024, and of the usual amber colour it presents in health. The pulse was slower and stronger ; the tongue clean; appetite good. The jaundiced appearance had almost quite passed off, and he had increased somewhat in weight. The inordinate thirst which was at first a marked feature had disappeared, and he had been at work for some weeks, and said he has not felt so well and strong for more than twelve months.

During treatment he twice neglected to take his koumiss for some days, and the effect was most noticeable. During these intervals no diminution of urine took place, but within forty-eight hours after resuming it the quantity began to diminish, and the diminution was continuous 